\title{
Smoking and Alcohol Consumption: A Study on Their Role as Risk Factors for Development of Laryngeal Squamous Cell Cancer
}

\author{
Sanjay Agrawal $1^{*}$, Ambad Ranjit² \\ ${ }^{1 * A s s o c i a t e ~ P r o f e s s o r, ~ D e p a r t m e n t ~ o f ~ E N T, ~}$ \\ ${ }^{2}$ Assistant Professor, Department of Biochemistry, \\ Chandulal Chandrakar Memorial Medical College, Kachandur, Durgapur, Chhatisgarh, India.
}

\begin{abstract}
Background: Among the head and neck carcinomas, laryngeal SCC is the most common one. Smoking and alcohol consumption are the indisputable risk factors of this carcinoma. Thus, we aimed to conduct this study, to assess the association of these factors with risk of development laryngeal cancer.

Methods: This study was a hospital based study consisting of 75 patients diagnosed with LSCC (Laryngeal squamous cell carcinoma) and 30 age and sex matched control.

Results: Out of 75 patients, $55(73.3 \%)$ were male and 20 $(26.7 \%)$ were female with male to female ratio $11: 4$. The patients at their ages of fifties and sixties showed higher incidence of LSCC. The percentage of incidence for age groups $45-55$ and 55-65 were respectively $33.3 \%$ and $29.3 \%$. We found that LSCC risk increased with increase in number as well as duration of cigarette smoking and alcohol intake whereas the risk reduced with the cessation; Odd Ratio $(O R)=5.01$ for those smoking for more than $30 \mathrm{yrs}, \mathrm{OR}=4.81$ for those taking $>30$ cigarettes per day in comparison to those with less duration and number of cigarette intake whereas $\mathrm{OR}=6.45$ for heavy drinkers, $\mathrm{OR}=2.91,1.81$ for moderate and light drinkers respectively.
\end{abstract}

\section{INTRODUCTION}

Tumours of head and neck occur at number of anatomical sites such as oral cavity, pharynx and larynx including their subparts. ${ }^{1}$ There are various risk factors associated with head and neck cancers such as smoking ${ }^{2}$, alcohol intake ${ }^{3}$ infection by human papilloma virus ${ }^{4}$ chronic gastroesophageal reflux ${ }^{5}$, exposure to asbestos, cement, nickel ${ }^{6}$, fossils fuels ${ }^{7}$ etc. Among these smoking and alcohol intake are considered as major risk factor which increase the malignant transformation risk by synergistic action. ${ }^{3}$

Moreover smoking and alcoholism are mostly involved in predisposing the risk of laryngeal cancer. ${ }^{8}$ Laryngeal cancer is the common type among the head and neck tumors accounting for about $30-40 \%$ of malignant tumour of head and neck. ${ }^{9}$ Over all in human body it comprises $1-2.5 \%$ of all malignancies. ${ }^{10}$ Histopathologically, squamous cell cancer is the major category of laryngeal cancer, involving almost $95-98 \%$ as shown in most studies. ${ }^{11}$
Conclusion: Thus laryngeal SCC must be prevented by encouraging elimination of smoking and alcohol consumption by educating and by giving an insight to the person indulged in such activities.

Key words: Laryngeal Squamous Cell Carcinoma, Smoking, Alcohol.

\section{${ }^{*}$ Correspondence to:}

\section{Dr. Sanjay Agrawal}

Associate Professor, Department of ENT,

Chandulal Chandrakar Memorial Medical College,

Kachandur, Durgapur, Chhatisgarh, India.

Article History:

Received: 04-08-2016, Revised: 23-08-2016, Accepted: 02-09-2016

\begin{tabular}{|l|c|}
\hline \multicolumn{2}{|c|}{ Access this article online } \\
\hline $\begin{array}{l}\text { Website: } \\
\text { www.jmmrp.com }\end{array}$ & Quick Response code \\
\hline DOl: & \\
10.21276/ijmrp.2016.2.6.040 & \\
\hline
\end{tabular}

Laryngeal carcinoma is mostly presented at the ages between 50 $75^{12}$ with higher prevalence among males. ${ }^{13}$ The male to female ratio of presentation of laryngeal squamous cell carcinoma varies from $4: 1-20: 1$. However the most common range is found to be 6:1 to $10: 1 .{ }^{9}$ American Cancer society cancer prevention studies conducted two studies commonly known as CPS I and CPS II in which the association of cigarette smoking and various cancer of oral cavity was investigated. In CPS I, smoking was associated with laryngeal and oropharyngeal cancer and risk ratios were found higher in men than in women. Likewise in CPS II, similar results were obtained but the risk ratios were found to be higher in females for laryngeal cancer in comparison to males. ${ }^{14}$

Although the exact mechanism behind development of cancer due to smoking and alcohol use is not clearly defined, it has been stated that during smoking larger tobacco particles are deposited in laryngeal mucosa. ${ }^{15}$ According to Martonen et al, mucosa of larynx is the site where cigarette smoke deposition occurs at a 
higher rate thereby making larynx vulnerable site to cancer in comparison to other airway regions. ${ }^{16}$ Similarly Yang et al showed about 3000 fold increase in incidence of upper respiratory tract than in case of lower parts. The possible reason for this may be limitation in the laminar flow of cigarette smoke in narrower larynx in contrast to other parts of airway. ${ }^{15}$ Chronic exposure of epithelium to cigarette smoke induces various morphological changes accompanied by chromosomal damage, activation of alveolar macrophages, production of hydrogen peroxide and superoxide which oxidatively damage DNA and increases the carcinogenic risk. ${ }^{17}$ Alcohol consumption along with smoking increase the risk of laryngeal cancer in multiplicative fashion. Alcohol causes increased absorption of tobacco in mucosal cell leading to activation of microsomal enzymes and production of tobacco carcinogen responsible for damaging DNA. ${ }^{18}$

Thus, it is essential to study the role of smoking and alcoholism on the development of laryngeal carcinoma, so that we can understand the cause of higher incidence, its prevention and facilitate the public health services.

\section{MATERIALS AND METHODS}

This study is hospital based study, carried out in the department of ENT GMC, Akola, Maharastra from 2013 to May 2015. In total 75 patients with laryngeal cancer verified histologically and 30 age and sex matched controls were included in the study. The controls and patients (diagnosed with laryngeal cancer) were interrogated using the structured questionnaire. The history of the participant was then recorded.

For the smoking case, questionnaire included were:

- If the participants were smokers or non-smokers

- If the participants are ex-smokers and time duration since smoking is ceased.

- Number of cigarette pack consumed/day.

- Age of start of smoking

For alcoholism case, questionnaire included were:

- If the participants consume alcohol or not

- Age of start alcohol consumption

- Number of drinks/week
Based on the data obtained the subjects were categorised as nondrinkers, light drinkers, moderate and heavy drinkers.

\section{Statistical Analysis}

The data obtained from the questionnaire was recorded and analysed using SPSS 11.0 software.

Table 1: Age wise distribution of case and control

\begin{tabular}{lccc}
\hline Age & Patients & Age & Control \\
\hline $\mathbf{2 5 - 3 5}$ & $5(6.7 \%)$ & $25-35$ & $3(10 \%)$ \\
$\mathbf{3 5 - 4 5}$ & $18(24 \%)$ & $35-45$ & $10(33.3 \%)$ \\
$\mathbf{4 5 - 5 5}$ & $25(33.3 \%)$ & $45-55$ & $6(20 \%)$ \\
$\mathbf{5 5 - 6 5}$ & $22(29.3 \%)$ & $55-65$ & $9(30 \%)$ \\
$\mathbf{6 5 - 7 5}$ & $5(6.7 \%)$ & $65-75$ & $2(6.7 \%)$ \\
Total & $75(100 \%)$ & Total & $30(100 \%)$ \\
\hline
\end{tabular}

Table 2: Gender wise distribution of case and control

\begin{tabular}{lcc}
\hline Gender & Patients & Controls \\
\hline Male & $55(73.3 \%)$ & $20(67 \%)$ \\
Female & $20(26.7 \%)$ & $10(33 \%)$ \\
Total & $75(100 \%)$ & $30(100 \%)$ \\
Male:Female & $11: 4$ & $2: 1$ \\
\hline
\end{tabular}

Table 3: Distribution of patients based on Smoking and drinking habit

\begin{tabular}{lc}
\hline Smoking and Drinking status & Number (\%) \\
\hline Ex-smokers & $10(13.3 \%)$ \\
Smokers & $17(22.7 \%)$ \\
Ex-drinkers & $7(9.3 \%)$ \\
Drinkers & $16(21.3 \%)$ \\
Both non-smokers and non-drinkers & $5(6.7 \%)$ \\
Both smokers and drinkers & $20(26.7 \%)$ \\
Total & $75(100 \%)$ \\
\hline
\end{tabular}

Table 4: Association of cigarette smoking with laryngeal cancer

\begin{tabular}{lccc}
\hline & Odd ratio & $\mathrm{Cl}$ (Confidence Interval) & P value \\
\hline $\begin{array}{l}\text { Non-smoker and non-drinkers } \\
\text { Ex-smoker (left smoking since) }\end{array}$ & 0.26 & $0.11-0.52$ & $>0.05$ \\
$\quad$ & & & \\
1-5 yr & 3.91 & $1.55-6.49$ & $<0.05$ \\
5-10yr & 3.06 & $1.15-5.28$ & $<0.05$ \\
10-15 yr & 2.17 & $1.02-4.81$ & $<0.01$ \\
Smokers & & & \\
Smoking for over 10 yrs & 2.51 & $1.02-5.88$ & $<0.05$ \\
Smoking for over 20yrs & 3.31 & $1.46-5.87$ & $<0.01$ \\
Smoking for over 30 yrs & 5.01 & $2.14-8.85$ & $<0.01$ \\
Intake of $>10$ cigarette/day & 2.62 & $1.02-5.22$ & $<0.05$ \\
Intake of $>20$ cigarette/day & 3.68 & $2.18-6.88$ & $<0.01$ \\
Intake of $>30$ cigarette/day & 4.81 & $2.77-9.17$ & $<0.01$ \\
\hline
\end{tabular}


Table 5: Association of alcohol drinking with laryngeal cancer

\begin{tabular}{lccc}
\hline Habit & OR & Cl & P \\
\hline $\begin{array}{l}\text { Non-smoker and non-drinkers } \\
\text { Ex-drinkers (left drinking since) }\end{array}$ & 0.26 & $0.11-0.52$ & $>0.05$ \\
$\quad$ 1-5 yrs & & & \\
5-10 yrs & 3.74 & $1.10-6.07$ & $<0.01$ \\
$\quad$ 10-15yrs & 2.11 & $1.03-3.71$ & $<0.01$ \\
Drinkers & 0.95 & $0.30-0.88$ & $<0.01$ \\
$\quad$ Light drinker (>7drinks/week) & & & \\
$\quad$ Moderate (1-2drinks/day) & 1.81 & $0.28-0.87$ & $<0.05$ \\
$\quad$ Heavy (4-5drinks/day) & 2.91 & $1.07-6.05$ & $<0.05$ \\
& 6.45 & $2.64-11.54$ & $<0.01$ \\
\hline
\end{tabular}

\section{RESULTS}

The patients mostly affected were at their fifth or sixth decades of ages. About $33.3 \%$ of patients in age group of $45-55$ and $29.3 \%$ in group of 55-65 years had laryngeal cancer. Out of 75 patients, $73.3 \%$ were male and $26.7 \%$ were females with the males: female ratio of $11: 4$. Among the patients with laryngeal cancer $6.7 \%$ were non-smoker and non-drinker, $13.3 \%$ were ex-smoker and $22.7 \%$ were smokers. Whereas $9.3 \%$ \& $21.3 \%$ were ex-drinkers and drinkers respectively. $26.7 \%$ were both smokers and drinkers.

There was significant association of laryngeal cancer with smoking status. There was significant difference $(p<0.05,0.01)$ in the risk of laryngeal cancer for smoking more than 10,20 and 30 years with the $\mathrm{OR}$ value and $\mathrm{Cl}$ value of $2.51,3.31,5.01$ and $1.02-5.88,1.46-5.87,2.14-8.85$ respectively than in comparison to control.

Similarly the number of cigarette intake per day was also strongly related to laryngeal cancer risk. Here we found higher risk in those patients smoking more than 30 cigarette per day $(\mathrm{OR}=4.81)$ in comparison to those taking more than 10 or 20 . The results were statistically significant $(P<0.05)$.

However in case of ex-smokers, there was decreased risk of laryngeal cancer in those who had stopped smoking since 10-15 years $(O R=2.17)$ in comparison to those who had left just before $5-10$ years $(O R=3.06)$ or $1-5$ years $(O R=3.91)$.

There was also significant association between the laryngeal cancer and drinking habit of the patients. Here we could find higher incidence of laryngeal cancer in patients consuming about 4-5drinks per day (OR=6.45 Cl= 2.64-11.54). In case of both smokers and drinkers (26.7\%), OR value obtained was 7.51 (Cl: 3.11-15.21).

\section{DISCUSSION}

About 88 to $98 \%$ of patients suffering from laryngeal cancer are smokers, which makes smoking a major risk factor for laryngeal carcinoma. ${ }^{19}$ In our study, about $22.7 \%$ of patients detected with laryngeal cancer were smokers, $21.3 \%$ were drinkers and $26.7 \%$ were both smokers and drinkers. In central Europe, $87 \%$ of LSCC are due to use of tobacco. ${ }^{20}$

Studies have shown strong association of cigarette smoking with laryngeal cancer. According to Maier and collegues, individuals indulged in smoking at early years of life are at higher risk of developing laryngeal cancer, as indicated by the OR values of 31.7 , for those persons who started smoking at or before 21 years of age and OR value of 7.7 for those individuals who began smoking at the ages ranging from 21-40 years. ${ }^{21}$ As demonstrated in Franchesch's study, smoking for more than 40 years significantly increased the risk of laryngeal SCC (OR 15.6) ${ }^{22}$ whereas smoking for lower durations presented lower risks (OR 2.13), as indicated in the study of Lee et al. ${ }^{23}$

In the present study, risk of laryngeal SCC was significantly high in those patients who smoked for more than 30 years $(O R=5.01)$ in comparison to those smoking for more than 20 years (OR= 3.31) and 10 years $(O R=2.51)$. In a view of Falk et al, there is a dose dependent relation between smoking and LSCC. ${ }^{24}$ The relative risk of developing LSCC were 4.4 folds for those who consumed half packet of cigarettes per day and 10.4 folds for those who used more than two packs per day, though, the number of cigarette smoked per day is also strongly associated to LSCC. ${ }^{20}$ In our study, we found strong association of LSCC with the patients smoking more than 30 cigarettes per day. Zatouski etal presented OR value of 59.7 for the patients smoking more than 30 cigarette per day. ${ }^{25}$ Researchers have proven that the derivatives of cigarette smoke such as nitrosamines and aromatic polycyclic hydrocarbons are the potent carcinogens in laryngeal epithelium causing DNA mutations, interruption in cell division and proliferation thereby inducing carcinogenesis. ${ }^{11}$ Tuyns et al suggested 16 fold increased risk of LSCC in heavy smokers than in controls. ${ }^{26}$ Use of black tobacco increases the risk due to high exposure to further carcinogens. ${ }^{27}$

Not only smoking but alcohol also has been regarded as the risk factor for LSCC in several studies. ${ }^{28}$ Ethanol, a major alcoholic beverage, though not considered as a carcinogen, can act as cofactor that can induce carcinogenesis by various mechanisms ${ }^{29}$ such as alcohol induced nutritional deficiencies, activation of other carcinogens and tobacco via induction of microsomal enzymes, ability to solubilise carcinogens and by facilitating penetration of laryngeal tissues by carcinogens. ${ }^{30}$ According to Koskinen et al, alcohol consumption is associated with higher risk of cancer and death. ${ }^{31}$ In the present study $9.3 \%$ of patients were ex drinkers and $21.3 \%$ were drinkers. We also found that the risk of laryngeal SCC increased with increased dose of alcohol. The risk was higher in heavy drinkers $(\mathrm{OR}=6.45)$ than in case of moderate and light drinkers $(\mathrm{OR}=2.91 \& 1.81)$ respectively.

Studies of Hashibe et al demonstrated higher risk of LSCC in the alcoholics $(\mathrm{OR}=36.7) .{ }^{20}$ This finding was supported by the study of Menach OP et al, who showed heavy drinkers to be at higher risks $(\mathrm{OR}=6.0)$ in comparison to control. ${ }^{32}$ In a German study $85.1 \%$ of LSCC patients consumed alcohol daily. Similarly another study reported that almost $76.3 \%$ of the patients drunk more than 25 grams of ethanol on daily basis ${ }^{21}$ whereas it was only $43.2 \%$ in case of study Markou K et al. ${ }^{8}$ 
However various studies have also suggested that cessation of smoking and drinking alcohol reduces the risk of LSCC, though the risk is still higher in comparison to controls. ${ }^{20}$ We found reduced risks of LSCC on ex-smokers and ex drinkers which was dependent on the duration of cessation. Those who had stopped smoking and drinking 10-15 years before were at reduced risk $(\mathrm{OR}=2.17,0.95$ for ex-smokers and ex-drinkers respectively) in comparison to those who stopped 1-5years (OR=3.91, 3.71 for exsmokers and ex-drinkers respectively) and 5-10 years ( $O R=3.06$, 2.11 for ex-smokers and ex-drinkers respectively) ago.

Tobacco smoke and alcohol act synergistically to promote laryngeal carcinogensis. Though the exact mechanism is still unclear ${ }^{33}$, several studies have elucidated the combined action of smoking and alcohol, showing the additive and multiplicative effects in comparison to controls. ${ }^{34}$ In our study we found highest risk of LSCC in the patients taking both cigarette and alcohol, OR 7.51 (Cl: 3.11-15.21).

Lewis et al elaborated that, glottis being the anatomically narrowest part of upper respirative tract, is more vulnerable to deposition of inhaled and ingested carcinogens. ${ }^{35}$ Further Renne et al stated that glottis being the transition zone (squamous epithelium to pseudostratified columnar epithelium), is at higher risk of metaplasia which can progress further to dysplasia and sequentially to invasive carcinoma with the repeated exposure to carcinogens. ${ }^{36}$

Ethanol acts as carcinogenic initiator, enhancing cellular permeability to other carcinogens mostly tobacco smoke. ${ }^{37}$ Enzyme alcohol dehydrogenase oxidises ethanol to acetaldehyde which is metabolised to acetate by aldehyde dehydrogenase. ${ }^{38}$ Acetaldehyde is grouped as $2 \mathrm{~B}$ human carcinogen suggesting increased risk of cancer with higher intake of alcohol. ${ }^{39}$

\section{CONCLUSION}

Since smoking and alcohol consumption are one of the major risk factors for LSCC, they should be refrained and preventive measures must be encouraged so as to support person indulged in smoking and alcohol intake to quit their use in order to reduce the incidence of laryngeal SCC.

\section{REFERENCES}

1. Jemal A, Siegel R, Ward E. Cancer statistics. CA Cancer J Clin., 2006; 56:106-130.

2. Sokic S I, Adanja B J, Marinkovic J P, Vlajinac H D. Case control study of risk factors in laryngeal cancer. Neoplasma, 1994; 41: 43-7.

3. Talamini R, Bosetti C, La Vecchia C, Dal Maso L, Levi F, Bidoli E, Negri E, Pasche C, Vaccarella S, Barzan L, Franceschi S. Combined effect of tobacco and alcohol on laryngeal cancer risk: a case-control study. Cancer Causes Control, 2002; 13:957-64.

4. Thekdi AA, Ferris RL. Diagnostic assessment of laryngeal cancer. Otolaryngol Clin North Am, 2002; 35:953-69.

5. Wight R, Paleri V, Arullendran P. Current theories for the development of nonsmoking and nondrinking laryngeal carcinoma. Curr Opin Otolaryngol Head Neck Surg., 2003; 11:73-7.

6. Dietz A, Ramroth H, Urban T, Ahrens W, Becher H. Exposure to cement dust, related occupational groups and laryngeal cancer risk: results of a population based case-control study. Int $\mathrm{J}$ Cancer, 2004; 108:907-11.
7. Elci OC, Akpinar-Elci M, Blair A, Dosemeci M. Risk of laryngeal cancer by occupational chemical exposure in Turkey. J Occup Environ Med, 2003; 45:1100-6.

8. Markou K, Christoforidou A, Karasmanis I, Tsiropoulos G, Triaridis S, Constantinidis I, Vital V, Nikolaou A. Laryngeal cancer: epidemiological data from Northern Greece and review of the literature. Hippokratia, 2013; 17(4): 313-8.

9. Makitie A, Pukander J, Raitiola H, Hyrynkangas K, Koivunen P, Virtaniemi J, Grenman R. Changing trends in the occurrence and subsite distribution of laryngeal cancer in Finland. Eur Arch Otorhinolaryngol, 1999; 256:277-9.

10. Parkin DM, Pisani P, Ferlay J. Estimates of the worldwide incidence of 25 major cancersin 1990.IntJCancer,1999;80:827-41. 11. Ballenger JJ, Snow JB. Otorhinolaryngology: head and neck surgery. 15th ed, Media, Williams \& Wilkins, PA, USA, 1996.

12. Jaseviciene J, Gurevicius R, Juozulynas A, Cicenas S. An evaluation of laryngeal cancer morbidity time trends in Lithuania. Rocz Akad Med Bialymst, 2003; 48:85-9.

13. Parkin DM, Bray F, Ferlay J, Pisani P. Global cancer statistics, 2002. CA Cancer J Clin., 2005; 55:74-108.

14. Freedman ND, Abnet CC, Leitzmann MF, Hollenbeck AR, Schatzkin A. Prospective Investigation of the Cigarette SmokingHead and Neck Cancer Association by Sex. Cancer, 2007; 110(7);1593-1601.

15. Yang CP, Gallagher RP, Weiss NS, Band PR, Thomas DB, Russell DA. Difference in incidence rates of cancers of the respiratory tract by anatomic subsite and histologic type: An etiologic implication. J Natl Cancer Inst., 1989; 81(23):1828-31.

16. Martonen TB. Surrogate Experimental Models for Studying Particle Deposition in the Human Respiratory Tract. Washington, DC: U Environmental Protection Agency; 1985.

17. Church DF, Pryor WA. Free-radical chemistry of cigarette smoke and its toxicological implications. Environ Health Perspect., 1985; 64:111-26.

18. Zeka A, Gore R, Kriebel D. Effects of alcohol and tobacco on aerodigestive cancer risks: a meta-regression analysis. Cancer Causes Control, 2003;14(9):897-906.

19. Monteiro E, Varzim G, Pires AM, Teixeira M, Lopes C. Cyclin D1 A870G polymorphism and amplification in laryngeal squamous cell carcinoma: implications of tumor localization and tobacco exposure. Cancer Detect Prev, 2004; 28:237-43.

20. Hashibe M, Boffetta P, Zaridze D, Shangina O, SzeszeniaDabrowska N, Mates D, Fabianova E, Rudnai P, Brennan P. Contribution of tobacco and alcohol to the high rates of squamous cell carcinoma of the supraglottis and glottis in Central Europe. Am J Epidemiol, 2007; 165:814-20.

21. Maier $\mathrm{H}$, Tisch $M$. Epidemiology of laryngeal cancer: results of the Heidelberg case-control study. Acta Otolaryngol Suppl., 1997; 527:160-4.

22. Hashibe M, Paul Brennan, Shuchun Chuang, Stefania Boccia, et al. Interaction between tobacco and alcohol use and the risk of head and neck cancer: pooled analysis in the International Head and Neck Cancer Epidemiology Consortium. Cancer Epidemiol Biomarkers Prev., 2009; 18(2):541-50.

23. Lee $Y C$, Marron M, Benhamou S. Active and involuntary tobacco smoking and upper aerodigestive tract cancer risks in a multicenter case-control study. Cancer Epidemiol Biomarkers Prev., 2009; 18(12):3353-61. 
24. Falk RT, Pickle LW, Brown LM, Mason TJ, Buffler PA, Fraumeni JF Jr. Effect of smoking and alcohol consumption on laryngeal cancer risk in coastal Texas. Cancer Res, 1989; 49:4024-9.

25. Zatonski W, Becher H, Lissowska J, et al. Tobacco, alcohol, and diet in the etiology of laryngeal cancer: a population-based case-control study. Cancer Causes Control, 1991; 2:3-10.

26. Tuyns AJ, Estève J, Raymond L, Berrino F, Benhamou $E$, Blanchet $F$. Cancer of the larynx/hypopharynx, tobacco and alcohol: IARC international case-control study in Turin and Varese (Italy), Zaragoza and Navarra (Spain), Geneva (Switzerland and Calvados (France). Int J Cancer, 1988; 41: 483-491.

27. Sancho-Garnier H, Theobald S. Black (air-cured) and blond (flue-cured) tobacco and cancer risk II: Pharynx and larynx cancer. Eur J Cancer, 1993; 29A: 273-276.

28. Altieri A, Bosetti C, Talamini R, Gallus S, Franceschi S, Levi F, Dal Maso L, Negri E, La Vecchia C. Cessation of smoking and drinking and the risk of laryngeal cancer. $\mathrm{Br} \mathrm{J}$ Cancer, 2002; 87:1227-9.

29. Seitz HK, Simanowski UA. Alcohol and carcinogenesis. Annu Rev Nutr., 1988; 8: 99-119.

30. Homann N, Seitz KH. Alcohol's effect on the development and progression of cancer. Nutr Clin Care, 2000;3:83-6.

31. Koskinen WJ, Broondbo K, Mellin Dahlstrand $H$, Luostarinen T, Hakulinen T, Leivo I, Molijn A, Quint WG, Roysland T, MunckWikland E, Makitie AA, Pyykko I, Dillner J, Vaheri A, Aaltonen LM. Alcohol, smoking and human papillomavirus in laryngeal carcinoma: a Nordic prospective multicenter study. J Cancer Res Clin Oncol, 2007;133:673-8.

32. Menach OP, Oburra HO, Patel A. Cigarette Smoking and Alcohol Ingestion as Risk Factors for Laryngeal Squamous Cell Carcinoma at Kenyatta National Hospital, Kenya. Clinical Medicine Insights: Ear, Nose and Throat, 2012:5 17-24.

33. Cattaruzza MS, Maisonneuve P, Boyle P. Epidemiology of laryngeal cancer. Eur J Cancer B Oral Oncol., 1996; 32B: 293305.
34. Menvielle G, Luce D, Goldberg P, Bugel I, Leclerc A. Smoking, alcohol drinking and cancer risk for various sites of the larynx and hypopharynx. A case-control study in France. Eur J Cancer Prev., 2004; 13(3):165-72.

35. Lewis DJ. Factors affecting the distribution of tobacco smokeinduced lesions in the rodent larynx. Toxicol Lett., 1981; 9(2):18994.

36. Renne RA, Gideon KM. Types and patterns of response in the larynx following inhalation. Toxicol Pathol., 2006; 34(3):281-5.

37. Mayne AT, Morse DE, Winn DM. Cancers of the oral cavity and pharynx. In: Schottenfeld D, Fraumeni JF Jr, eds. Cancer Epidemiology and Prevention. 3rd ed. New York, NY: Oxford University Press, Inc; 2006:674-696..

38. Zakhari S. Overview: how is alcohol metabolized by the body? Alcohol Res Health, 2006; 29(4):245-254.

39. Marshall JR, Freudenheim J. Alcohol. In: Schottenfeld D, Fraumeni JF Jr, eds. Cancer Epidemiology and Prevention. 3rd ed. New York, NY: Oxford University Press, Inc; 2006: 243-258.

\section{Source of Support: Nil.}

Conflict of Interest: None Declared.

Copyright: (c) the author(s) and publisher. IJMRP is an official publication of Ibn Sina Academy of Medieval Medicine \& Sciences, registered in 2001 under Indian Trusts Act, 1882.

This is an open access article distributed under the terms of the Creative Commons Attribution Non-commercial License, which permits unrestricted non-commercial use, distribution, and reproduction in any medium, provided the original work is properly cited.

Cite this article as: Sanjay Agrawal, Ambad Ranjit. Smoking and Alcohol Consumption: A Study on Their Role as Risk Factors for Development of Laryngeal Squamous Cell Cancer Int J Med Res Prof. 2016; 2(6):191-95. DOI:10.21276/ijmrp.2016.2.6.040 